\title{
Factors associated with adherence to medication among depressed patients from Saudi Arabia: a cross-sectional study
}

This article was published in the following Dove Press journal:

Neuropsychiatric Disease and Treatment

28 October 2014

Number of times this article has been viewed

\author{
Khalaf Al Jumah' \\ Mohamed Azmi Hassali \\ Dalal AI Qhatani' \\ Kamal El Tahir ${ }^{3}$ \\ 'Department of Pharmacy, Al Amal \\ Psychiatric Hospital, Riyadh, Saudi \\ Arabia; ${ }^{2}$ School of Pharmaceutical \\ Sciences, Universiti Sains Malaysia, \\ Penang, Malaysia; ${ }^{3}$ College of \\ Pharmacy, King Saud University, \\ Riyadh, Saudi Arabia
}

Background: Several studies have investigated the factors associated with adherence to antidepressants, with inconsistent conclusions. However, no similar study has investigated this issue among patients diagnosed with major depressive disorder in Saudi Arabia. The aim of this study is to explore patients' adherence to antidepressant medications, and the factors associated with adherence.

Methods: A non-experimental cross-sectional design was used to measure adherence to antidepressants among major depressive disorder patients, and the factors associated with adherence. The patients were recruited from the outpatient clinic at the Al-Amal Complex for Mental Health in Riyadh, Saudi Arabia, between August 2013 and January 2014. Eligible participants met with one of the research coordinators for assessment of their adherence. Adherence was investigated indirectly by use of the Morisky Medication Adherence Scale, and patients' beliefs were assessed through the Beliefs about Medicine Questionnaire. Information about the severity of their depression, demographics, and other study variables were collected.

Results: A total of 403 patients met the inclusion criteria and participated in the study. Of those, $203(50.37 \%)$ were females, while the remaining 200 (49.6\%) were males. There was an average age of 39 years (standard deviation, \pm 11 years). Half of the patients $(52.9 \%)$ reported low adherence to their antidepressant medication, with statistically significant differences between the low adherence and high adherence scores relating to sex, age, and duration of illness.

Conclusion: Low medication adherence is a common problem among major depressive disorder patients in Saudi Arabia. Medication-taking behavior among depressed patients is influenced by several factors, mainly patients' beliefs regarding antidepressants. This study has improved the understanding of the factors associated with adherence to antidepressants.

Keywords: patient compliance, predictors, antidepressants, patients' beliefs, depression, psychiatry

\section{Introduction}

Adherence to medications is an essential step in the management of chronic diseases. ${ }^{1,2}$ Adherence has been defined in different ways; the World Health Organization defines it as "the extent to which a person's behaviour, taking medication, following a diet, and/or executing lifestyle changes, corresponds with agreed recommendations from a healthcare provider". ${ }^{2}$ Non-adherence could be intentional or unintentional behavior; ${ }^{3}$ if a patient does not take the medicine either because of forgetfulness or lack of access, this type of non-adherence is unintentional. In contrast, if the patient does not follow the prescription because of his or her personal beliefs or evaluation of the medicine, then it is called intentional non-adherence. ${ }^{3}$
Correspondence: Khalaf Al Jumah Department of Pharmacy, Al Ama Psychiatric Hospital, PO Box 33626 , Riyadh II458, Saudi Arabia

Email khalafaljumaah@yahoo.com 
Major depressive disorder is a major public health challenge due to its high prevalence, it is estimated to affect $15 \%$ of the general population, and is being seen as a global disease burden. ${ }^{4}$ Major depressive disorder is one of the most disabling diseases, disrupting daily life, activities, and work. It is believed that major depressive disorder will become the second largest cause of disease burden in the next two decades. ${ }^{5,6}$ Major depressive disorder is also a common health problem in Saudi Arabia, where the prevalence is increasing. A previous study in Saudi Arabia estimated the prevalence of depression at $18 \% .^{7}$ The World Health Organization estimates that $50 \%$ of all depression patients have not been treated, and it is therefore expected that antidepressant use and other treatment options will increase on a global level. ${ }^{8}$

Although antidepressant medications are proven to be effective, many patients do not receive an adequate dosage for an adequate duration, and the medication's effectiveness is further reduced due to non-adherence. ${ }^{9}$ National and international therapeutic guidelines stress the importance of continuing antidepressants for at least 9 months. ${ }^{10,11}$ It has been found that $28 \%$ of patients discontinue medication after 1 month, and between $44 \%$ and $52 \%$ of patients discontinue medication after 3 months. ${ }^{10,12}$ Data from the Gulf countries revealed that $88 \%$ of Kuwaiti patients with major depressive disorder are non-adherent to their antidepressant medications. ${ }^{13-15}$ Unfortunately, there are no data from Saudi Arabia regarding patients' adherence to antidepressants, and one cross-sectional study reported that only $60 \%$ of depressed patients adhere to their psychiatric clinic visits. ${ }^{16}$ Few studies from Saudi Arabia have investigated adherence to medication and factors associated with adherence among non-psychiatric, chronically ill patients. ${ }^{17,18}$

Several studies have investigated the factors associated with adherence to antidepressant medication, ${ }^{6,9,19,20}$ and the results from a recent review show that factors associated with adherence to antidepressants and sociodemographic indictors are inconsistent. ${ }^{6}$ Certain factors have been identified as predictors of adherence to antidepressant medication, including sociodemographic factors, educational level, clinical factors (eg, severity of symptoms), quality of life, and side effects. ${ }^{6,9}$ In addition, evidence showed that patients' beliefs about antidepressant medication can affect patients' adherence. ${ }^{21}$ Based on similar factors, Horne's Theoretical Model of medication can be used to identify patients' behaviors, showing that they depend upon patients' perceived need for treatment (necessity) and on concerns about the possibly harmful effects of the medication. ${ }^{22}$ According to this theory, if the necessity for treatment is greater than the concern about adverse effects, the adherence will be strong; if the concerns are greater than the necessity, then the adherence will be poor. ${ }^{21}$ Furthermore, the impact of beliefs on adherence varies according to culture. ${ }^{23}$ While beliefs about medication have been studied intensely, little is known about depressed patients' beliefs toward antidepressants in Saudi Arabia, and whether their beliefs affect their medication use behavior. Furthermore, little is known about the influence of other factors on medication use in Saudi Arabia.

The purpose of this study was to explore patients' adherence to antidepressant medication, and the factors associated with adherence among depressed patients.

\section{Methods}

A non-experimental cross-sectional design was used to measure adherence to antidepressants among major depressive disorder patients, and to explore the factors associated with adherence. Patients were recruited from outpatient clinics of the Al Amal Complex for Mental Health in Riyadh, Saudi Arabia between August 2013 and January 2014. Al Amal Complex has 500 beds and provides psychiatric care to the whole population of the capital city (Riyadh) of Saudi Arabia.

\section{Study population}

All patients meeting the following inclusion criteria were invited sequentially to participate after a briefing about the objectives of the study: 1) patients within the age range of 18 to 60 years; 2) patients diagnosed with major depressive disorder, according to the Diagnostic and Statistical Manual of Mental Disorders; 3) patients with a history of disease for at least 6 months; and 4) patients who were prescribed at least one antidepressant medication. Patients having history of psychosis, bipolar disorder, drug dependency, or who were prescribed concomitant medications other than antidepressants were excluded from the study. A written consent was sought from the patients, and eligible participants met with one of the research coordinators for assessment of adherence, the patient's beliefs, severity of symptoms, demographics, and other study variables.

\section{Ethical considerations}

Ethical approval was granted by the local training and research committee at Al Amal hospital, Riyadh, Saudi Arabia. 


\section{Statistical methods and sample size}

To calculate the sample size, it was taken into account that the average percentage of low adherence among depressed patients is $52 \% .^{12,16}$ With a confidence level of $95 \%$, a total of 401 patients was needed to conduct the study. Descriptive and comparative statistics were carried out using the Statistical Package for Social Sciences, version 17 (SPSS Inc., Chicago, IL, USA). Analyses of covariance were conducted to assess differences in medication adherence, beliefs, and depression severity between groups. Independent samples $t$-test was conducted to compare overall mean adherence between groups. To investigate the relation and correlation between factors and adherence, both a Pearson correlation coefficient and a multiple regression (stepwise method) were used.

\section{Adherence and medication beliefs}

Patients' adherence was assessed by an Arabic version of the Morisky Medication Adherence Scale (MMAS), ${ }^{24}$ a wellvalidated instrument developed by Morisky et al. ${ }^{25-28}$ MMAS has good validity and reliability, has also been proven to be a useful screening technique for antidepressant medications, ${ }^{29}$ and has been validated on other Arabic patients suffering from chronic diseases. ${ }^{24,30,31}$ MMAS consists of eight items that address specific medication-taking behavior and adherence. The first seven items have dichotomous responses (yes/ no), and they are formulated in a way to avoid an acquiescence bias. The total score of MMAS ranges from 0 to 8 , with higher scores representing better adherence. Those who score less than 6 are considered to have poor adherence, and those who score 6 or more are considered to be high adherers. Written permission to use the questionnaire was obtained from its authors.

Specific and general beliefs of patients were assessed by using the Arabic version of the Beliefs about Medicine Questionnaire (BMQ-Specific and BMQ-General), ${ }^{24}$ a selfreporting measure of proven validity, reliability, and psychometric capability, with both general medical patients and with depressed patients. ${ }^{21,32,33}$ The BMQ-Specific contains two parts, "Specific Necessity", which evaluates patients' views about the necessity and importance of their medication, and "Specific Concerns", which questions patients' beliefs about the potential harm and adverse effects of their own medications. Each part of the questionnaire has a potential score ranging from five to 25 . The BMQ-General also has two parts, "General-Harm", which measures beliefs that medicines in general are harmful, addictive, or poisonous, while the second part, "General-Overuse" measures beliefs that medicines in general are over-used by doctors..$^{33}$ Again, written permission was obtained from the original author.

\section{Results}

A total of 403 patients met the inclusion criteria and participated in this study. Patients' characteristics are shown in Table 1. Exactly 203 patients, representing $50.4 \%$ of the total study sample, were females, and the remaining 200 patients (49.6\%) were males. Participants' ages ranged from 18 to 60 years, with an average of 39 years (standard deviation [SD], \pm 11 years). A proportion or $36.9 \%$ of the participants were uneducated, or had only finished a few years of primary school. The majority of the participants $(82.4 \%)$ were using one antidepressant medication, with an average illness duration of more than 5 years.

Almost half of the patients $(52.9 \%)$ reported low adherence to their antidepressant medication. The average MMAS score was 5.23, and details of patients' self-reported adherence behavior, according to the MMAS, are shown in Table 2. A statistically significant difference in adherence level is shown in favor of the male sex, older age, patients with a shorter duration of illness, and those having more than three follow-up visits with a psychiatric clinic per year, shown in detail in Table 1. On the other hand, the number of medications per prescription, and the pharmacological group of the antidepressant medication, were not significantly associated with adherence level to antidepressant medication.

Both low- and high-adherence groups scored high in the necessity beliefs, with scores of 18.02 (SD, \pm 3.91 points) and 18.32 (SD, \pm 3.9 points), respectively, with no statistically significant difference. In contrast, patients with high adherence had significantly lower levels of concern about antidepressant medication, and significantly lower harmful beliefs. In addition, high-adherence patients reported less severity of depression on the Montgomery-Åsberg Depression Scale (Table 3).

Using Pearson's correlation coefficient to examine the relationship between factors and adherence behavior resulted in a negative association between adherence and specific belief concerns. There was also a negative association between general overuse belief, general harm belief and severity of depression (measured by the Montgomery-Åsberg Depression Scale), as shown in Table 4. On the other hand, there was no positive association between the adherence score and the other proposed factors. However, when using the multiple linear regression stepwise method for certain variables, dependent on the adherence scores and after adjusting for other covariables, it was found that belief concerns 
Table I Characteristics of study participants and their level of adherence

\begin{tabular}{|c|c|c|c|}
\hline Factor & Frequency (\%) & Adherence, mean & Standard deviation \\
\hline \multicolumn{4}{|l|}{ Sex } \\
\hline Male* & $200(49.6)$ & 5.72 & \pm 1.84 \\
\hline Female & $203(50.4)$ & 4.75 & \pm 1.95 \\
\hline \multicolumn{4}{|l|}{ Age (years) } \\
\hline $18-30$ & $102(25.1)$ & 5.55 & \pm 1.73 \\
\hline $31-40$ & $120(29.9)$ & 4.77 & \pm 2.10 \\
\hline $4 I-50$ & $102(25.1)$ & 4.65 & \pm 1.95 \\
\hline $51-60 *$ & $80(19.8)$ & 6.09 & \pm 1.66 \\
\hline \multicolumn{4}{|l|}{ Education level } \\
\hline No formal education & $90(22.5)$ & 4.86 & \pm 2.02 \\
\hline Primary & $58(14.4)$ & 5.42 & \pm 1.84 \\
\hline Intermediate & $80(19.8)$ & 4.84 & \pm 2.02 \\
\hline Secondary & $130(32.1)$ & 5.60 & \pm 2.03 \\
\hline College/bachelor's degree & $45(11.2)$ & 5.06 & \pm 1.52 \\
\hline \multicolumn{4}{|c|}{ Number of antidepressant drugs currently taken } \\
\hline One & $331(82.3)$ & 5.19 & \pm 1.98 \\
\hline Two & $72(17.7)$ & 5.24 & \pm 1.90 \\
\hline \multicolumn{4}{|c|}{ Number of clinic visits per year } \\
\hline One & $28(7.0)$ & 4.25 & \pm 1.87 \\
\hline Two & $4 I(10.2)$ & 5.09 & \pm 1.92 \\
\hline Three & $149(36.9)$ & 4.67 & \pm 1.98 \\
\hline Four* & $185(46.0)$ & 5.79 & \pm 1.81 \\
\hline \multicolumn{4}{|l|}{ IIIness duration } \\
\hline Three years or less** & II4 (28.3) & 5.57 & \pm 1.80 \\
\hline Between 3 and 6 years & $92(23.0)$ & 5.52 & \pm 1.89 \\
\hline Between 6 and 9 years & $172(42.8)$ & 4.95 & \pm 1.96 \\
\hline More than 9 years & $23(5.9)$ & 3.95 & \pm 2.39 \\
\hline
\end{tabular}

Notes: Student's $t$-test was used for the differences in the characteristics of the study according to the level of adherence. *Significant at the $P=0.00 \mathrm{I}$ level. **Significant at the $P=0.05$ level.

( $\left.R=0.40 ; P<0.001, R^{2}=0.162\right)$ were the most important predictor associated with adherence to antidepressants; general harm and severity of depression in different levels of association, were also associated with adherence to antidepressants, as shown in Table 5.

\section{Discussion}

To the best of our knowledge, this is the first study to investigate factors associated with adherence among Saudi major depressive disorder patients, using a validated tool to measure patients' adherence and beliefs. However, a limited study has

Table 2 Participants' reported adherence behavior by MMAS-8

\begin{tabular}{|c|c|}
\hline Item & $\begin{array}{l}\text { Percentage }(\%) \text { of } \\
\text { patients who answered yes }\end{array}$ \\
\hline When you travel or leave home, do you sometimes forget to bring along your medication? & 51.3 \\
\hline $\begin{array}{l}\text { People sometimes miss taking their medications for reasons other than forgetting. Thinking over the past two } \\
\text { weeks, were there any days when you did not take your medicine? }\end{array}$ & 48. 1 \\
\hline $\begin{array}{l}\text { Have you ever cut back or stopped taking your medication without telling your doctor, because you felt worse } \\
\text { when you took it? }\end{array}$ & 46.8 \\
\hline Do you sometimes forget to take your medicine? & 40.6 \\
\hline When you feel like your health condition is under control, do you sometimes stop taking your medicine? & 39.0 \\
\hline $\begin{array}{l}\text { Taking medication every day is a real inconvenience for some people. Do you ever feel hassled about sticking } \\
\text { to your treatment plan? }\end{array}$ & 31.0 \\
\hline \multicolumn{2}{|l|}{ How often do you have difficulty remembering to take all your medications? } \\
\hline Never & 87.7 \\
\hline Once in a while & 7 \\
\hline Sometimes & 3.6 \\
\hline Usually & 1.7 \\
\hline All of the time & 0 \\
\hline
\end{tabular}

Abbreviation: MMAS-8, eight-item Morisky Medication Adherence Scale. 
Table 3 Patients' beliefs about antidepressants, the severity of their depression, and their level of adherence

\begin{tabular}{|c|c|c|c|c|c|c|}
\hline \multirow[t]{2}{*}{ Factor } & \multicolumn{2}{|c|}{ Low adherence $(\mathrm{N}=2 \mid 4)$} & \multicolumn{2}{|c|}{ High adherence $(\mathrm{N}=189)$} & \multirow[t]{2}{*}{ t-value } & \multirow[t]{2}{*}{$P$-value } \\
\hline & Mean & Standard deviation & Mean & Standard deviation & & \\
\hline General overuse & 12.75 & 2.50 & 12.18 & 2.49 & 1.549 & 0.123 \\
\hline General harm* & 11.74 & 2.67 & 10.11 & 2.45 & 4.319 & 0.000 \\
\hline Necessity beliefs & 18.02 & 3.91 & 18.32 & 3.90 & 0.520 & 0.603 \\
\hline Belief concerns* & 14.30 & 3.50 & 11.82 & 3.03 & 5.153 & 0.000 \\
\hline Montgomery-Åsberg Depression Scale* & 25.75 & 13.66 & $|7.6|$ & 10.92 & 4.519 & 0.000 \\
\hline
\end{tabular}

Note: *Significant at the $P=0.001$ level.

Abbreviation: $\mathrm{N}$, number of patients.

reported medication adherence among non-psychiatric Saudi patients, for example AlHewiti et a $\mathrm{l}^{18}$ reported adherence and beliefs about medications among primary health care patients in Riyadh; also, Khan and et al ${ }^{34}$ reported adherence among diabetics attending primary health centers in the Al Hasa district, Saudi Arabia.

The current study indicated that the majority of patients with major depressive disorder reported low adherence (52.9\%). These findings are similar to those of two other studies conducted on chronic diseases in Riyadh and the Al Hasa region of Saudi Arabia, both of which found low adherence to medication, in a range from $51 \%$ to $57.5 \% .^{18,34}$

There were high specific necessity belief scores among patients in both the low- and high-adherence groups in the current study, with a slightly higher score in the high-adherence group. The high-necessity belief scores were associated with the high average age of the population included in the study. This finding is also supported by another study. ${ }^{35} \mathrm{In}$ the current study, adherence was found to be influenced by specific belief concerns, general harm, and overuse beliefs about antidepressant medications, all of which are similar to the findings of other studies. ${ }^{6,18}$

Low adherence to antidepressant medications and severity of depression had a negative correlation, with a significance at the $P=0.01$ level, which is compatible with results of Roca et al ${ }^{36}$ and Russell et al $;{ }^{37}$ however, other studies did not find a relationship between adherence and severity of depression. ${ }^{6}$ This finding can be explained by an inverse causal association, suggesting that adherence to a treatment regimen may lead to a better clinical outcome. ${ }^{20}$

Other factors associated with low adherence included younger age. This could reflect the fact that younger patients have had less experience with the disease and its medications. It is also possible that the more common side effects of weight gain and impaired sexual function are of particular concern to younger patients. ${ }^{20}$ On the other hand, the high adherence scores among patients who have more follow-up visits with a psychiatrist per year could be related to the effect of physician-patient contact and the patient's satisfaction. ${ }^{38}$

This study has a few limitations. First, the study design is cross-sectional and therefore cannot determine causation unless there is narrative evidence to support the findings; also, non-experimental design led us to recruit patients sequentially and non-randomly. Second, the use of selfreporting scales alone is a limitation. However, all scales used in this study were selected carefully, relying on wellproven tests already validated with Arabic patients. ${ }^{23,24}$ Furthermore, patients who report low adherence are most likely to be truthful. ${ }^{18}$ Finally, the influence of the researchers during the collection of data from patients can lead to bias, but this is believed to have had a minimal effect on the study outcome.

Further studies are needed to examine the impact of interventions targeting those factors that have correlated with adherence to antidepressants. For example, specific belief concerns, general harm, and overuse beliefs about

Table 4 Multiple regression (stepwise method) for study of characteristics influencing adherence (model summary)

\begin{tabular}{|c|c|c|c|c|c|c|}
\hline & $r$ & $r^{2}$ & $\beta$ (unstandardized) & $\beta$ (standardized) & t-value & $\begin{array}{l}P \text {-value } \\
\text { (significance } \\
\text { level) }\end{array}$ \\
\hline Belief concerns & 0.402 & 0.162 & -0.157 & -0.282 & 4.306 & $\begin{array}{l}0.000 \\
(0.01)\end{array}$ \\
\hline General harm & 0.472 & 0.223 & -0.147 & -0.201 & 3.027 & $\begin{array}{l}0.003 \\
(0.01)\end{array}$ \\
\hline $\begin{array}{l}\text { Montgomery-Åsberg } \\
\text { Depression Scale }\end{array}$ & 0.527 & 0.278 & -0.036 & -0.242 & 3.805 & $\begin{array}{l}0.000 \\
(0.01)\end{array}$ \\
\hline
\end{tabular}


Table 5 Pearson correlation coefficients between study characteristics and adherence

\begin{tabular}{ll}
\hline Factor & Correlation coefficient \\
\hline General overuse & $-0.1512^{*}$ \\
General harm & $-0.3472^{* *}$ \\
Necessity beliefs & 0.0081 \\
Belief concerns & $-0.4019^{* *}$ \\
Montgomery-Åsberg Depression Scale & $-0.3276^{* *}$ \\
\hline
\end{tabular}

Notes: *Correlation is significant at the 0.05 level (two-tailed). **Correlation is significant at the 0.01 level (two-tailed).

antidepressants, and severity of depression, should all be further investigated.

\section{Conclusion}

Low adherence is a common health problem among depressed patients in Saudi Arabia and is influenced, as explained by Horne's theoretical model, ${ }^{33}$ by high belief concerns and high general harm beliefs regarding antidepressants. This study has improved the understanding of factors associated with adherence to antidepressants, and their relationship. This understanding should help caregivers and stakeholders to improve the management and clinical outcomes of depressed patients by addressing their medication-taking behavior using a systematic approach.

\section{Disclosure}

The authors report no conflicts of interest in this work.

\section{References}

1. Osterberg L, Blaschke T. Adherence to medication. New Engl J Med. 2005;353(5):487-497.

2. Burkhart PV, Sabaté E. Adherence to long-term therapies: evidence for action. J Nurs Scholarsh. 2003;35(3):207.

3. Unni EJ, Farris KB. Unintentional non-adherence and belief in medicines in older adults. Patient Educ Couns. 2011;83(2):265-268.

4. Moussavi S, Chatterji S, Verdes E, Tandon A, Patel V, Ustun B. Depression, chronic diseases, and decrements in health: results from the World Health Surveys. Lancet. 2007;370(9590):851-858.

5. Murray CJ, Lopez AD. Alternative projections of mortality and disability by cause 1990-2020: Global Burden of Disease Study. Lancet. 1997;349(9064):1498-1504.

6. Rivero-Santana A, Perestelo-Perez L, Pérez-Ramos J, Serrano-Aguilar P, De Las Cuevas C. Sociodemographic and clinical predictors of compliance with antidepressants for depressive disorders: systematic review of observational studies. Patient Prefer Adherence. 2013;7:151-169.

7. Al-Khathami AD, Ogbeide DO. Prevalence of mental illness among Saudi adult primary-care patients in Central Saudi Arabia. Saudi Med J. 2002;23(6):721-724.

8. Dijkstra A, Jaspers M, van Zwieten M. Psychiatric and psychological factors in patient decision making concerning antidepressant use. J Consult Clin Psychol. 2008;76(1):149-157.

9. Hansen HV, Kessing LV. Adherence to antidepressant treatment. Expert Rev Neurother. 2007;7(1):57-62.
10. Katon W, Von Korff M, Lin E, Bush T, Ormel J. Adequacy and duration of antidepressant treatment in primary care. Med Care. 1992;30(1): $67-76$.

11. Keller MB. The long-term treatment of depression. J Clin Psychiat. 1998;60:41-45.

12. Bulloch AG, Patten SB. Non-adherence with psychotropic medications in the general population. Soc Psychiatry Psychiatr Epidemiol. 2010; 45(1):47-56.

13. Al-Qasem A, Smith F, Clifford S. Adherence to medication among chronic patients in Middle Eastern countries: review of studies. East Mediterr Health J. 2011;17(4):356-363.

14. Al-Saffar N, Deshmukh A, Carter P, Adib S. Effect of information leaflets and counselling on antidepressant adherence: open randomised controlled trial in a psychiatric hospital in Kuwait. Int J Pharm Pract. 2005;13(2):123-131.

15. Al-Jumah KA, Qureshi NA. Impact of pharmacist interventions on patients' adherence to antidepressants and patient-reported outcomes: a systematic review. Patient Prefer Adherence. 2011;6:87-100.

16. Alhulwah LM, Alhathloul AM, Alblowi AS, Alyahya KM. Long term antidepressants prescribing in the Psychiatry Department at Riyadh Military Hospital. Saudi Med J. 2011;32(10):1051-1054.

17. Tourkmani AM, Al Khashan HI, Albabtain MA, Al Harbi TJ, Al Qahatani HB, Bakhiet AH. Medication adherence among patients in a chronic disease clinic. Saudi Med J. 2012;33(12):1278-1284.

18. Alhewiti A. Adherence to long-term therapies and beliefs about medications. Int J Family Med. 2014;2014:479596.

19. Banerjee S, Varma RP. Factors affecting non-adherence among patients diagnosed with unipolar depression in a psychiatric department of a tertiary hospital in Kolkata, India. Depress Res Treat. 2013;2013: 809542.

20. Tamburrino MB, Nagel RW, Chahal MK, Lynch DJ. Antidepressant medication adherence: a study of primary care patients. Prim Care Companion J Clin Psychiatry. 2009;11(5):205-211.

21. Hunot VM, Horne R, Leese MN, Churchill RC. A cohort study of adherence to antidepressants in primary care: the influence of antidepressant concerns and treatment preferences. Prim Care Companion J Clin Psychiatry. 2007;9(2):91-99.

22. Clifford S, Barber N, Horne R. Understanding different beliefs held by adherers, unintentional nonadherers, and intentional nonadherers: application of the Necessity-Concerns Framework. J Psychosom Res. 2008;64(1):41-46.

23. Horne R, Graupner L, Frost S, Weinman J, Wright SM, Hankins M. Medicine in a multi-cultural society: the effect of cultural background on beliefs about medications. Social Sci Med. 2004;59(6):1307-1313.

24. Alhalaiqa F, Deane KH, Nawafleh A, Clark A, Gray R. Adherence therapy for medication non-compliant patients with hypertension: a randomised controlled trial. J Hum Hypertens. 2011;26(2):117-126.

25. Morisky DE, Ang A, Krousel-Wood M, Ward HJ. Predictive validity of a medication adherence measure in an outpatient setting. J Clin Hypertens (Greenwich). 2008;10(5):348-354.

26. Morisky DE, Green LW, Levine DM. Concurrent and predictive validity of a self-reported measure of medication adherence. Med Care. 1986; 24(1):67-74.

27. Krousel-Wood M, Islam T, Webber LS, Re RN, Morisky DE, Muntner P. New medication adherence scale versus pharmacy fill rates in seniors with hypertension. The Am J Manag Care. 2009;15(1):59-66.

28. Morisky DE, DiMatteo MR. Improving the measurement of self-reported medication nonadherence: response to authors. $J$ Clin Epidemiol. 2011;64(3):255-257.

29. George CF, Peveler RC, Heiliger S, Thompson C. Compliance with tricyclic antidepressants: the value of four different methods of assessment. Br J Clin Pharmacol. 2000;50(2):166-171.

30. Sweileh WM, S Ihbesheh M, Jarar IS, et al. Antipsychotic medication adherence and satisfaction among Palestinian people with schizophrenia. Curr Clin Pharmacol. 2012;7(1):49-55. 
31. Sweileh WM, Ihbesheh MS, Jarar IS, et al. Self-reported medication adherence and treatment satisfaction in patients with epilepsy. Epilepsy Behav. 2011;21(3):301-305.

32. Mårdby AC, Akerlind I, Jörgensen T. Beliefs about medicines and self-reported adherence among pharmacy clients. Patient Educ Couns. 2007;69(1-3):158-164.

33. Horne R, Weinman J, Hankins M. The beliefs about medicines questionnaire: the development and evaluation of a new method for assessing the cognitive representation of medication. Psych Health. 1999;14(1):1-24.

34. Khan AR, Al-Abdul Lateef ZN, Al Aithan MA, Bu-Khamseen MA, Al Ibrahim I, Khan SA. Factors contributing to non-compliance among diabetics attending primary health centers in the Al Hasa district of Saudi Arabia. J Family Community Med. 2012;19(1):26-32.
35. Aikens JE, Nease DE Jr, Klinkman MS. Explaining patients' beliefs about the necessity and harmfulness of antidepressants. Ann Fam Med. 2008;6(1):23-29.

36. Roca M, Armengol S, Monzón S, Salva J, Gili M. Adherence to medication in depressive patients. J Clin Psychopharmacol. 2011;31: 541-543.

37. Russell J, Kazantzis N. Medication beliefs and adherence to antidepressants in primary care. N Z Med J. 2008;121:14-20.

38. Liekens S. Patients'Beliefs Towards Antidepressants: Narrative Review of the Literature [doctoral thesis]. Leuven: Katholieke Universiteit; 2012.
Neuropsychiatric Disease and Treatment

\section{Publish your work in this journal}

Neuropsychiatric Disease and Treatment is an international, peerreviewed journal of clinical therapeutics and pharmacology focusing on concise rapid reporting of clinical or pre-clinical studies on a range of neuropsychiatric and neurological disorders. This journal is indexed on PubMed Central, the 'PsycINFO' database and CAS,

\section{Dovepress}

and is the official journal of The International Neuropsychiatric Association (INA). The manuscript management system is completely online and includes a very quick and fair peer-review system, which is all easy to use. Visit http://www.dovepress.com/testimonials.php to read real quotes from published authors.

Submit your manuscript here: http://www.dovepress.com/neuropsychiatric-disease-and-treatment-journal 